\title{
USO VARIÁVEL DAS OCLUSIVAS ALVEOLARES /t, d/ EM FLORIANÓPOLIS
}

\author{
VARIATION IN THE USE OF ALVEOLAR PLOSIVES /T,D/ IN THE CITY OF \\ FLORIANÓPOLIS
}

Eva Christina O. Dias ${ }^{1}$

Mestranda do Programa de Pós-graduação em Linguística - UFSC.

\begin{abstract}
Resumo
O presente trabalho constitui-se em um estudo sociolinguístico da variação dos segmentos fonológicos /t, d/ quando se realizam foneticamente diante de vogal alta posterior $[\mathrm{u}] \mathrm{na}$ região de Florianópolis. As variantes concorrentes são as oclusivas alveolares [t, d] e as aspiradas $\left[\mathrm{t}^{\mathrm{h}}, \mathrm{d}^{\mathrm{h}}\right]$. O trabalho tem como objetivo geral analisar essa variação linguística, com destaque para a aspiração, cujo fenômeno não está previsto no inventário fonético do português brasileiro. A base de dados foi coletada a partir de entrevistas com seis informantes florianopolitanos e organizada em dois grupos de fatores sociais: sexo e idade. O estudo sociolinguístico de Pagotto (2004) e o trabalho dialetológico de Furlan (1989) serviram como principal fonte de consulta no que se refere aos dados variáveis. Constatase, a partir da análise dos dados, que existe variação entre a oclusiva não-aspirada e a aspirada, sobretudo em contexto diante de pausa.
\end{abstract}

Palavras-chave: Variação de oclusivas alveolares. Aspiração. Vogal alta posterior.

\begin{abstract}
The present research is a sociolinguistic study about the variation of the phonological segments /t, d/ that are phonetically produced in front of high back vowel [u], in the city of Florianópolis. Their possible allophones alveolar plosives [t,d] and aspirated plosives [th, $\mathrm{dh}$ ], respectively. The main objective is the analysis of such linguistic variation, especially in relation to aspiration, since this phenomenon is not present in the phonetic inventory of Brazilian Portuguese. Data was collected through interviews from six participants who are originally from Florianópolis, and it was divided into two different groups, according to sex and age. The theoretical framework related to such variability was mainly supported by the studies of Pagotto (2004) and Furlan (1989). Data analyses showed the presence of variation between the plosive and its aspirated counterpart, mostly in front of a pause.
\end{abstract}

Keywords: Variation of alveolar plosives. Aspiration. High back vowel.

\footnotetext{
${ }^{1}$ Este trabalho foi desenvolvido para a disciplina de Linguística Geral, ministrada no primeiro semestre de 2009, sob orientação da professora Edair Görski.
} 


\section{ILHA DE SANTA CATARINA: PALCO DE DIVERSIDADE LINGUÍSTICA}

Florianópolis, capital de Santa Catarina, apresenta atualmente uma grande diversidade linguística proveniente de um processo de crescimento galopante iniciado na década de 1970. A população triplicou nesse período, passando de 115 mil para 396 mil habitantes (IBGE, 2007).

A cidade, que compreende a ilha e parte do continente, não é a mais populosa do Estado, nem um pólo industrial econômico. O processo de migração acelerado deveu-se a vários fatores, dentre os quais podemos destacar a demanda de serviço público, a boa qualidade de vida proporcionada pela natureza insulana e a ascensão do turismo na cidade.

O resultado dessa migração é a grande quantidade de florianopolitanos que não são "ilhéus" ou "manezinhos", assim chamados os habitantes nativos da cidade. Em decorrência dos contatos dialetais, abunda variação linguística na cidade e o falar típico local entra em confronto com os falares oriundos das regiões de onde chegam novos habitantes da Ilha.

A diversidade sociocultural em Florianópolis motivou este estudo a apoiar-se na teoria da variação linguística, iniciada por William Labov (1972). A Sociolinguística Variacionista considera a língua como um sistema heterogêneo e estuda as comunidades de fala a partir de coleta de dados que se aproximam da fala natural. Nessa perspectiva, são relevantes os fatores sociais, como idade, sexo e escolaridade, para analisar as variações do sistema linguístico em suas diversas áreas, como fonologia, morfologia, sintaxe e discurso. Esta pesquisa utiliza amostras de fala de florianopolitanos e se insere na área da fonologia, sendo embasada pela teoria da variação linguística.

Apesar do contato dialetal existente, Florianópolis apresenta algumas características que tornam o seu falar bastante peculiar em relação a outros dialetos de origem predominantemente portuguesa. Uma das características mais evidentes no falar "manezinho" é ausência da africação de /t,d/ - realizadas pelos alofones [t $\left.\int, \mathrm{d}_{3}\right]^{2}$-, presente em outras variantes no Brasil, como em tipo, ['tfipu] e médico, ['medfiku], por exemplo³. Os falantes típicos nativos tendem a não reproduzir essa africação, que envolve a região palatal, mantendo o ponto de articulação alveolar; assim, as palavras tipo e médico são realizadas, em geral, como ['tipu] e ['mediku].

\footnotetext{
${ }^{2}$ As barras / / servem para indicar a representação fonológica, que corresponde aos fonemas - com função distintiva na língua, diferenciando-se da representação fonética, que corresponde aos alofones, os sons na realização da fala, indicada por colchetes [ ]. Assim, a palavra pote tem sua forma fonológica /'pote/, mas se realiza foneticamente de distintas maneiras, como ['pote], ['poti] e ['pot $\left.\int i\right]$. A fonte usada para a transcrição é Doulos SIL, disponível em http://www.fon.hum.uva.nl/praat/download_win.html.

${ }^{3}$ O processo de palatalização é comumente usado na literatura como sinônimo de africação. Porém, Cagliari (1998) distingue africação e palatalização, referindo-se ao primeiro como um processo que envolve o modo de articulação - de oclusiva para fricativa - e ao segundo como a mudança de ponto de articulação - de alveolar para palato-alveolar. Pagotto (2004, p. 230) observa também que “a africação e a alteração de ponto de articulação deveriam ser processos separados” e identifica em sua análise os alofones [t,d] como não africados, [ts, dz] como africados não palatais e [t $\int$, d3] como africados palatais.
} 
A variação das consoantes oclusivas alveolares é mencionada em Cristófaro Silva (2006) como um processo de alofonia, que, visto pela perspectiva da Fonologia de Laboratório, envolve o caráter gradiente do contínuo sonoro. A gradiência -mudanças suaves ao longo do tempo de realização - de um processo como africação compreende, nesse sentido, os detalhes fonéticos, como a aspiração, característicos das línguas e dialetos.

Os segmentos /t, d/ apresentam diferentes características na cadeia da fala. Uma delas é o efeito de aspiração, que consiste em um efeito acústico gerado pela distensão da glote numa forte emissão de ar no momento da produção das oclusivas, simbolizado pelo diacrítico [h], muito comum na língua inglesa, como na palavra tore $\left[\mathrm{t}^{\mathrm{h}} \mathrm{ox}\right.$, por exemplo. É importante frisar que as africadas, citadas anteriormente, e as aspiradas são diferentes, embora, como observa Pagotto (2004, p. 230), "a africação e a aspiração das consoantes alveolares devem ser fenômenos relacionados, uma vez que ocorrem nos mesmos contextos”. Enquanto as primeiras são simbolizadas por [ $\left.\mathrm{t} \int, \mathrm{d} 3\right]$, como em oito e pode, ['ojt $\left.\int \mathrm{v}\right]$ e ['podzI], as segundas são representadas pelo o símbolo h sobrescrito, [ ], assim temos ['ojt $\left.{ }^{\mathrm{h}} \mathrm{U}\right]$ e ['pod $\left.{ }^{\mathrm{h}} \mathrm{I}\right]$, por exemplo.

Os sons aspirados não são considerados como variantes - alofones - no quadro fonético do português. Porém, o estudo sociolinguístico de Pagotto (2004, 206) menciona a possibilidade de considerar "uma oclusiva dental/alveolar com efeito de aspiração" como uma das variantes dos fonemas $/ \mathrm{t}, \mathrm{d} /$. Desse modo, os vocábulos tímido e pente, por exemplo, se realizariam como [?t? sobre a gradação na realização fonética - que evidencia detalhes diferenciais entre uma oclusiva aspirada e uma africada, o autor observa que "não é totalmente descabido pensar que haja uma relação entre africação e a aspiração, especialmente se levarmos em conta que o dialeto de Florianópolis não apresenta nenhuma regra categórica para a realização de tais consoantes" (PAGOTTO, 2004, p. 230).

Apesar de o autor ter identificado e descrito o fenômeno da aspiração pela óptica da Fonologia de Geometria de Traços, ele não contabiliza as variantes aspiradas em sua análise quantitativa devido à dificuldade de distingui-las auditivamente e, por isso, acaba optando por considerá-las, conforme suas palavras, "ou simplesmente alveolar (ou seja, sem africação) ou uma africada alveolar conforme o grau de estridência.” (PAGOTTO, 2004, p. 206).

O objeto deste estudo é a variação das oclusivas alveolares /t,d/ em posição diante de vogal alta posterior [u]. Como variantes concorrentes são consideradas as oclusivas alveolares [t, d] e as oclusivas alveolares aspiradas $\left[\mathrm{t}^{\mathrm{h}}, \mathrm{d}^{\mathrm{h}}\right]$. Então, serão analisadas palavras como tu e dado, por exemplo, quando realizadas como ['tu] e ['dadu] ou como ['t $\left.\mathrm{t}^{\mathrm{h}} \mathrm{u}\right]$ e ['dad $\left.{ }^{\mathrm{h}} \mathrm{u}\right]$.

Apesar de predominarem na literatura pesquisas referentes às oclusivas alveolares diante de [i], optou-se, neste estudo, em analisar o contexto diante de vogal $[\mathrm{u}]^{4}$. A escolha foi

\footnotetext{
${ }^{4}$ Fant (1973, apud PAGOTTO, 2004, p. 226) analisa a relação entre a aspiração das oclusivas e as vogais que as seguem. O resultado é o aumento de duração das vogais altas [i] e [u].
} 
motivada por observações informais em conversas. Causou estranhamento a percepção da frequência de realização do fenômeno de aspiração nesse ambiente fonológico. Deste modo, o levantamento do corpus de análise foi direcionado para que houvesse produção nesse contexto (cf. Seção 4).

O trabalho consiste em uma análise quantitativa baseada em frequências, com dados obtidos a partir da fala de informantes florianopolitanos com ascendência também nativa. $\mathrm{O}$ objetivo é verificar se há variação na produção das oclusivas no contexto diante de [u] e se algum dos fatores controlados, descritos na seção de Metodologia mais adiante, favorece seu aparecimento. Considerando a identificação do fenômeno de aspiração na variável /t,d/ diante da vogal alta [i] feita por Pagotto (2004), sugere-se como hipótese que ocorrerá variação também no contexto diante da vogal alta [u].

Os tópicos sequenciam-se partindo de uma descrição das variantes de origem açoriana, com base em Furlan (1989), e de uma descrição atual das variáveis /t,d/, segundo Pagotto (2004). Em seguida será discutido o fenômeno da aspiração do ponto de vista fonológico, considerando Pagotto (2004), Cagliari (1998) e Cristófaro Silva (2006). Antes da análise de dados, apresenta-se o suporte teórico-metodológico, com base em Pagotto (2004), Battisti et al. (2007) e Pires (2007). Finalmente, a análise dos dados das entrevistas tentará relacionar os resultados com os pontos teóricos expostos.

\section{A REALIZAÇÃO DE /t/ $\mathrm{E}$ /d/ NO DIALETO FLORIANOPOLITANO: VARIANTES AÇORIANAS E LOCAIS}

Nesta seção, pretende-se resgatar nos estudos de Furlan (1989) a variação registrada como fenômeno característico do falar açoriano-catarinense, para compará-la, a seguir, com o quadro de variação encontrado em Pagotto (2004), referente ao dialeto florianopolitano atual.

\subsection{A vertente açoriana}

Dizer qual é a variante original do dialeto florianopolitano é, no mínino, problemático. Em primeiro lugar, porque não existia um aparato tecnológico para gravar os primeiros povoados de origem portuguesa que surgiram no século XVII; em segundo lugar, porque a pequena população açoriana que se implantava aqui era proveniente de diferentes ilhas do Arquipélago dos Açores - São Jorge, São Miguel, Graciosa, Terceira, etc. Ou seja, há, desde o início da colonização, contato de diferentes grupos sociais: imigrantes de distintos povoados açorianos instalam-se numa região já habitada por tupis-guaranis.

Segundo Furlan (1989), alguns dados contradizem a hipótese da influência açoriana sobre o falar característico de Florianópolis. O autor observa que nenhum estudo catarinense tratou formalmente da questão e isso constitui um dos motivos que obscurece a tese da influência açoriana. 
Porque quase nada de específico se conhece do(s) falar(es) dos Açores, do Brasil e, particularmente, de Santa Catarina até fins do século 19 e porque a questão em apreço se situa em área de natureza eminentemente movediça, uma tese não pode ser considerada sólida antes que se demonstre sua consistência de todos os pontos de vista (FURLAN, 1989, p. 52).

Para Rogers (1947, apud FURLAN, 1989, p. 49), que visitou as principais metrópoles brasileiras, as mudanças fonéticas percebidas seguiam as tendências do português europeu e, por isso, as características fonéticas de Portugal deveriam ser consideradas como ponto de partida de análise e não as das ilhas açorianas.

Soma-se à falta de estudos sólidos o fato de que, historicamente, o dialeto açoriano e o florianopolitano têm uma mesma base, o português europeu, o que significa que traços que relacionam o falar de Florianópolis com o de Açores podem ser, na verdade, característicos de um mesmo dialeto, o português ibérico.

Feitas essas ressalvas, Furlan (1989) analisa dados relativos ao léxico e à fonética açoriana, comparando-os com os traços atuais, com o objetivo de identificar a vertente que torna o falar açoriano de Santa Catarina diferente dos outros dialetos do Estado 5 . Em relação às variáveis $/ \mathrm{t}, \mathrm{d} /$, o autor considera que existe a variante africada, definindo-a como "a consoante de tensão oclusiva e distensão fricativa” (FURLAN, 1989, p. 134). Observa, ainda, dois níveis de africação decorrente do processo de assimilação progressiva da fricativa: $\mathrm{t}>\mathrm{ts}>\mathrm{tj}$ (FURLAN, 1989, p. 135):

O contexto em que a africação ocorre difere do de outros falares [...] não é do falar carioca, no qual são africados /t,d/ seguidos de /i/ ou [j], como em tio, dia [...] No açoriano catarinense, o fenômeno limita-se à oclusiva surda /t/, quando vem precedida de vogal tônica $+/ \mathrm{j} /$ e seguida de vogal recuada [u], não havendo sido registrados casos para a sonora /d/; manifestam-se, às vezes num mesmo falante, as duas fases do mesmo fenômeno de assimilação parcial, a saber:

i)palato-alveolarização do /t/, do que resulta uma africação, cuja distensão palatal é pouco tensa; ex.: oito ['ojtšu], gaita ['gajtša] ${ }^{6}$;

ii) palatalização do /t/; ex.: oito ['ojtju], gaita ['gajtja].

Segundo a análise do autor, /t,d/ em palavras como leite, pente, tio não sofre africação nem palatalização no falar açoriano catarinense, diferentemente do dialeto carioca. A variação identificada em Furlan (1989) está condicionada pelo contexto diante de ditongo com glide anterior [j] e pode ser esquematizada da seguinte maneira:

\footnotetext{
${ }^{5}$ O estudo de Furlan (1989) é parte dos resultados das pesquisas feitas para seu trabalho de doutorado. O autor observa, na introdução, a dificuldade em encontrar dados devido à falta de documentação específica sobre a origem dos dialetos catarinenses, e, por isso, buscou em uma vasta bibliografia sobre o português ibérico e americano as variantes diacrônicas e atuais (FURLAN, 1989, p. 18).

${ }^{6}$ O símbolo [ť̃] representa para Furlan (1989) a africação realizada na região palato-alveolar. Em Pagotto (2004, p. 206), a variante africada palato-alveolar é simbolizada por [t $\int$, que será mencionada na seção 2.2.
} 


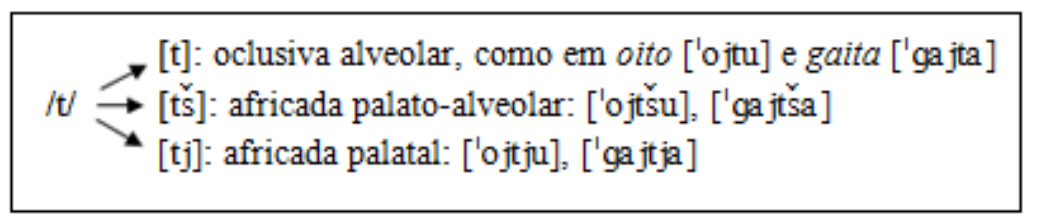

FIGURA 1: Representação da variável linguística /t/ e suas variantes, condicionadas pelo contexto precedido de ditongo com glide anterior [j], segundo Furlan (1989).

Podemos notar que a variação depende do glide [j] e da vogal posterior, ou recuada, [u], além disso, percebemos que a variação se limita à oclusiva surda /t/. Furlan (1898) observa que não há registro de variação com a oclusiva sonora /d/.

\subsection{Variantes na fala atual}

Como foi mencionado na introdução, o falar florianopolitano apresenta características peculiares em relação aos demais dialetos brasileiros. Pagotto (2004) avalia como singular o ritmo acelerado que dificulta a compreensão de quem não é nativo; a realização da vogal baixa /a/ quase como um shwá [ ], vogal quase imperceptível, típica do português ibérico, e, ainda, a entoação bastante aguda, com ascendência em final de frase, fenômeno que, segundo o autor, “ainda não recebeu nenhum estudo” (PAGOTTO, 2004, p. 43).

O autor realiza um estudo sobre o fenômeno de variação que ocorre em Florianópolis com as consoantes /t/ e /d/ em contexto diante de vogal alta anterior [i] ou glide [y] $]^{7}$, como em tímido e índio, por exemplo. O conjunto de variantes identificadas em seu estudo pode ser representado da seguinte forma:

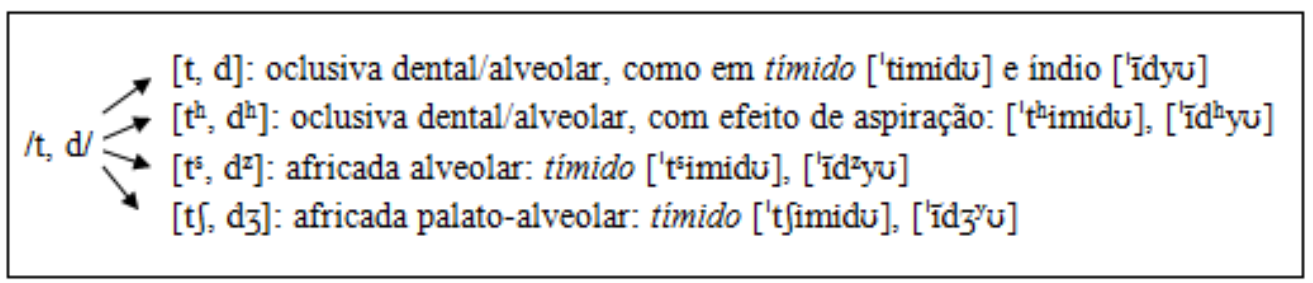

FIGURA 2: Representação da variável linguística /t,d/ e suas variantes, condicionadas pelo contexto seguido de vogal anterior [i] ou glide anterior [j], segundo Pagotto (2004).

Pagotto (2004, p. 206) observa que a variação de /t, d/ pode ocorrer também no contexto entre ditongo com glide anterior [y] e vogal posterior [u], como em oito e doido, por exemplo. Nesse caso, pode ocorrer ou uma africada palato-alveolar, ['oyt $\int u$ ] e ['doyt $\int u$, ou uma oclusiva com articulação secundária em glide, ['oytsu] e ['doytsu].

\footnotetext{
${ }^{7}$ O glide, ou semivogal, é representado em Furlan (1989) como [j]. Ambos os símbolos são usados na Fonética.
} 
A partir das Figuras 1 e 2, pode-se perceber que há uma diferença entre o conjunto de variação identificado por Pagotto (2004) e aquele assinalado em Furlan (1989). Podemos contrastá-los, observando que:

(i) o contexto condicionante à variação da oclusiva na pesquisa de Furlan (1989) é o precedente, ditongo com glide [j] e independe do posterior, enquanto, em Pagotto (2004), é o seguinte, vogal [i], e independe do anterior. Ou seja, há uma inversão de posição de contextos condicionantes.

(ii) a variação identificada por Pagotto (2004) atinge a sonora /d/, enquanto em Furlan (1989) a variação se reduz ao segmento surdo.

(iii) entre as variantes apresentadas na Figura 2, encontra-se a oclusiva aspirada, ausente na figura anterior.

Como a oclusiva aspirada constitui a variante concorrente neste trabalho, o tópico a seguir se dedica a descrever a aspiração do ponto de vista fonológico e discutir suas características no quadro de variação das oclusivas alveolares.

\section{PROCESSO FONOLÓGICO DE ASPIRAÇÃO: TRATA-SE DE VARIAÇÃO/ ALOFONIA LINGUÍSTICA?}

Os sons [t] e [d] são tradicionalmente chamados de oclusivos alveolares, diferenciando-se entre si pelo vozeamento ou não das pregas vocais: [t] é surdo, enquanto [d] é sonoro. Pela perspectiva da fonologia baseada em traços distintivos, as consoantes aspiradas são entendidas como um segmento que é produzido com a glote - abertura das pregas vocais distendida, sendo marcado pelo traço [+aspirado], e que, auditivamente é percebido pelo som gerado com uma forte corrente de ar que sai das pregas vocais estiradas (BISOL, 1999). A aspiração é, muitas vezes, dificilmente percebida pelo ouvido ${ }^{8}$, por isso, o critério de seleção na contagem de dados analisados para este trabalho foi o ruído perceptível acusticamente, gerado quando a consoante tem forte aspiração.

A realização da oclusiva aspirada ainda não está presente no quadro de variação fonética do português, ou seja, não faz parte de seu inventário de alofones. Porém, estudos recentes apontam para uma alta ocorrência de aspiração no português do Brasil, chamando a atenção para um possível caso de variação. Em um dos trabalhos realizados pelo grupo de estudos do Laboratório de Circuitos e Processamento de Sinais (LINSE) ${ }^{9}$ sobre o português do Brasil, observa-se que "as variantes aspiradas não são descritas como alofones das oclusivas surdas. No entanto, temos observado em análises de sinal de fala que ocorre

\footnotetext{
${ }^{8}$ Do ponto de vista da Fonética Acústica, a oclusiva aspirada é identificada segundo seu VOT - o tempo entre a explosão da oclusiva e o início do vozeamento vocálico (CHO; LADEFOGED, 1999), um período medido na escala de milissegundos.

9 O LINSE - Laboratório de Circuitos e Processamento de Sinais - é uma unidade de pesquisa do Departamento de Engenharia Elétrica da Universidade Federal de Santa Catarina (Brasil) e desenvolve pesquisa em sistemas de conversão texto-fala.
} 
aspiração em diversas oclusivas surdas com uma alta taxa de ocorrência, especialmente nos contextos alveolar e velar" (ALVES et al., 2008) ${ }^{10}$.

Cristófaro Silva (2006) observa que, entre a mudança discreta de uma oclusiva a uma africada, existe espaço para a ocorrência de outros fenômenos, como o desvozeamento, a palatalização e a aspiração, que refletem a variabilidade de realizações de tal processo: 't, $\mathrm{t}^{\mathrm{h}}, \mathrm{t}^{\mathrm{j}}, \mathrm{t} \int \mathrm{e}$ ' $\mathrm{d},{ }^{\circ} \mathrm{d}, \mathrm{d}^{\mathrm{j}}, \mathrm{d} \mathrm{z}^{\prime}$. Podem-se questionar, então, os critérios usados para a discretização diante do caráter difuso de um fenômeno como a transformação de uma oclusiva em uma africada.

Isso não significa, aponta a autora, que não exista categorização, mas mostra que devemos pensar na premissa teórica de que as abstrações são concebidas sem a contribuição da variabilidade. De fato, adquirimos a língua em meio à variação: "podemos argumentar que a variabilidade propicia a necessidade de abstração” (CRISTÓFARO SILVA, 2006, p.32).

Em Florianópolis, o fenômeno de aspiração é observado em Pagotto (2004), que considera sua realização como uma "oclusiva dental/alveolar com efeito de aspiração" (PAGOTTO, 2004, p.206). Em sua descrição, o autor destaca a grande aproximação da variante africada alveolar [ts] e da aspirada [ $\left.\mathrm{t}^{\mathrm{h}}\right]$, que ocorrem nos mesmos contextos, gerando dificuldades em distinguir os dois fenômenos.

\section{METODOLOGIA}

O estudo foi feito a partir de dados orais gravados obtidos através de entrevistas realizadas com seis indivíduos florianopolitanos, selecionados por apresentarem a fala característica da região e por terem ascendência também nativa.

\subsection{Os informantes e a entrevista}

Do grupo de informantes, três são homens, apresentando 48, 46 e 28 anos e três são mulheres, com idades de 47, 27 e 22 anos. Desse modo, foram considerados dois grupos sociais, com três integrantes para cada um: sexo (masculino e feminino) e idade (faixa etária de 20 a 30 e de 40 a 50 anos). Todos eles são nascidos em Florianópolis e têm pais nativos também. O Quadro 1 apresenta a distribuição dos informantes segundo o gênero e a idade.

\footnotetext{
10 "aspirated variants are not described as voiceless stop allophones. However, we have observed in speech signal analyses that aspiration occurs for any voiceless stop with a high occurrence rate, especially in alveolar and velar contexts” (ALVES et al., 2008).
} 
QUADRO 1: Distribuição dos informantes de acordo com o gênero e a idade

\begin{tabular}{c|c|c}
\hline Informantes & Sexo/gênero & Idade \\
\hline 1 & masculino & 48 anos \\
\hline 2 & masculino & 46 anos \\
\hline 3 & masculino & 28 anos \\
\hline 4 & feminino & 47 anos \\
\hline 5 & feminino & 27 anos \\
\hline 6 & feminino & 22 anos \\
\hline
\end{tabular}

A fim de especificar mais detalhadamente o quadro de informantes, podemos caracterizálos segundo sua escolaridade e local de residência. Todos completaram o Ensino Médio, mas apenas o informante 5 concluiu a faculdade. Em relação à moradia, todos sempre residiram em Florianópolis: o informante 1 nasceu na zona rural - no bairro Lagoa da Conceição, localizado no interior da Ilha-, mas mora há 20 anos no bairro Estreito, considerado parte da zona central; os informantes 2 e 5 sempre residiram no bairro Tapera, situada na zona rural, e os informantes 3, 4 e 6 sempre viveram no bairro Estreito, zona central.

Os dados foram coletados por meio de uma entrevista (anexo) constituída de três partes. Na primeira, há cinco perguntas com respostas livres, mas somente as três últimas foram contabilizadas, porque as duas primeiras serviram de instrumento de familiarização do interlocutor com a entrevista. Na segunda parte, o informante lê uma notícia adaptada de jornal e, na terceira, ele lê 26 frases dirigidas.

Os vocábulos analisados foram selecionados a partir das três partes da entrevista: fala espontânea, leitura de texto e leitura de frases dirigidas. É importante salientar que o objeto de estudo não foi revelado até o final da entrevista e, por isso, optou-se por iniciar a entrevista com perguntas de fala espontânea, já que as frases dirigidas apresentam alta frequência de palavras com a variável dependente controlada na pesquisa.

\subsection{As variáveis controladas}

As variáveis dependentes observadas (nosso objeto de estudo) são as consoantes oclusivas alveolares $/ \mathrm{t}, \mathrm{d} /$, realizadas diante de vogal alta posterior [u], como em tu e ato - nesta última palavra tem-se a vogal final [u] decorrente da elevação da vogal média /o/. O objetivo é verificar se há variação nesse contexto linguístico, observando duas variantes: as oclusivas alveolares simples [t,d] e as oclusivas alveolares aspiradas $\left[\mathrm{t}^{\mathrm{h}}, \mathrm{d}^{\mathrm{h}}\right]$.

Conforme mencionado na seção anterior, o efeito de aspiração não é facilmente percebido auditivamente. Por isso, ao selecionar as variantes, o critério de distinção entre elas foi a presença ou não do ruído gerado pela forte expulsão de ar logo após a explosão da consoante: em [t,d] não há percepção de ruído, em [ $\left.\mathrm{t}^{\mathrm{h}}, \mathrm{d}^{\mathrm{h}}\right]$ o ruído é perceptível e que pode ser visualizado a partir de uma análise espectrográfica. 
O grupo de fatores linguísticos controlado é a pausa após a vogal alta [u] para o qual foram considerados dois fatores: posição medial no vocábulo ou grupo fonético, e posição diante de pausa, em final de vocábulo. O seguinte trecho, extraído da segunda parte da entrevista (anexo), exemplifica esses contextos:

(1)Elas só serão liberadas para uso em grande escala após terem mostrado (pausa), durante (sem pausa) os testes, eficácia e segurança.

O estudo de Pagotto (2004) apresentou o contexto de pausa como favorável à ocorrência de africação (PAGOTTO, 2004, p. 282). Conforme mencionado na Seção 1, as oclusivas aspiradas foram incluídas no grupo das africadas, o que justifica a seleção do contexto de pausa na pesquisa.

Em relação aos fatores sociais, foram considerados a idade e o sexo/gênero. O controle do primeiro se apoia na hipótese de que a idade representa correlato primário para o processo de mudança. De acordo com Chambers (2002, apud BATTISTI, 2007, p.355), “a mudança prototípica é revelada em um teste padrão por meio do qual uma pequena variação no discurso da geração mais velha ocorre com maior frequência na geração média e com uma frequência ainda maior na geração a mais nova.” 11

Para Pagotto (2004), a idade é um dos fatores mais relevantes na determinação do processo de variação e mostrou-se influente no processo de variação estudado, já que os resultados obtidos apontaram maior frequência de realização da variante africada palatal entre os mais jovens do que entre os mais velhos. O autor observa que "a faixa etária mais jovem parece embarcar na aventura da modernidade, rejeitando a forma não africada e adotando mais fortemente a forma africada palatal, enquanto a faixa etária mais alta permanece como mantenedora da forma não africada” (PAGOTTO, 2004, p. 398).

O segundo fator social, o gênero, foi controlado considerando a hipótese de existir uma correlação entre o sexo e o processo de palatalização. Pagotto (2004), com base em estudos de Haeri (1996, apud PAGOTTO, 2004, p. 406), observa que “[...] os homens seriam, em geral os propulsores de processos fonéticos na região posterior da cavidade bucal e as mulheres, responsáveis por inovações na região anterior. Este seria o caso da palatalização”. Apesar de seus resultados não apresentarem o fator sexo como relevante, o autor aponta essa hipótese como importante para futuras investigações.

Acredita-se, com base nesses estudos, que haverá mais variação no contexto linguístico pausa do que em posição dentro de vocábulo; e que, entre os grupos sociais, os informantes do sexo feminino e os da faixa etária menor produzirão o maior número de aspiradas.

\footnotetext{
11 “change reveals itself prototypically in a pattern whereby some minor variant in the speech of the older generation occurs with greater frequency in the middle generation and with still greater frequency in the youngest generation.” (CHAMBERS, 2002, apud BATTISTI, 2007, p.355)
} 


\section{ANÁLISE DOS DADOS}

Foram levantadas 367 ocorrências de /t,d/ diante de [u] (96 dados provenientes da leitura do texto, 156 da leitura de frases e mais 115 dados colhidos da parte livre da entrevista). Esses dados estão distribuídos conforme a Tabela 1.

TABELA 1: Distribuição das variantes

\begin{tabular}{c|c|c|c}
\hline \multicolumn{3}{c}{ Variantes } \\
\hline [t, d] & \multicolumn{2}{c}{$\left[\mathbf{t}^{\mathbf{h}}, \mathbf{d}^{\mathbf{h}}\right]$} \\
\hline Ocorrência & Porcentagem & Ocorrência & Porcentagem \\
\hline $302 / 367$ & $82 \%$ & $65 / 367$ & $18 \%$ \\
\hline
\end{tabular}

Parece que o fenômeno da aspiração é significante na análise da variação da oclusiva alveolar condicionada ao contexto seguido de vogal posterior, pois a percentagem de ocorrência da oclusiva aspirada foi de 18\%. É importante ressaltar que não houve realização da variante africada palato-alveolar [t $\int, \mathrm{d}_{3}$ ] e da africada alveolar [ts, dz], previstas em Pagotto (2004) nesse contexto.

Conforme descrito na Seção 4.1, a entrevista constitui-se de três partes: fala espontânea, leitura de texto e leitura de frases dirigidas. Considerando-se que os contextos de leitura podem influenciar o informante a tentar se aproximar do texto escrito e que na fala espontânea há menor atenção à pronúncia, os dados estão distribuídos na tabela abaixo conforme os tipos de contexto da entrevista para verificar se isso influencia na produção da variável.

TABELA 2. Distribuição das variantes segundo o contexto da entrevista

\begin{tabular}{|c|c|c|c|c|}
\hline \multirow{3}{*}{ Contexto da entrevista } & \multicolumn{4}{|c|}{ Variantes } \\
\hline & \multicolumn{2}{|c|}{$[t, d]$} & \multicolumn{2}{|c|}{$\left[t^{h}, d^{h}\right]$} \\
\hline & Ocorrência & Porcentagem & Ocorrência & Porcentagem \\
\hline Fala espontânea & $106 / 115$ & $92 \%$ & 9/115 & $8 \%$ \\
\hline Leitura do texto & $72 / 96$ & $75 \%$ & $24 / 96$ & $25 \%$ \\
\hline $\begin{array}{c}\text { Leitura das frases } \\
\text { dirigidas }\end{array}$ & $125 / 156$ & $80 \%$ & $31 / 156$ & $20 \%$ \\
\hline
\end{tabular}

Observa-se pela Tabela 2 que, percentualmente, no contexto fala espontânea, [t, d] ocorre em $92 \%$ dos casos e $\left[\mathrm{t}^{\mathrm{h}}, \mathrm{d}^{\mathrm{h}}\right]$ ocorre em apenas $8 \%$. Nos contextos de leitura, a percentagem de ocorrência da aspirada $\left[\mathrm{t}^{\mathrm{h}}, \mathrm{d}^{\mathrm{h}}\right]$ aumenta, correspondendo a 20 e $25 \%$, enquanto a percentagem da oclusiva [t, d] diminui para $75 \%$ e $80 \%$ do total. Esse resultado será importante para entender o resultado relativo ao fator linguístico pausa, apresentado a seguir. 


\subsection{O grupo de fatores lingüísticos pausa}

Na tabela 3, apresentamos os resultados relacionados ao contexto linguístico pausa. Houve pausa em 123 contextos, e, em 214, não houve.

TABELA 3. Resultado da variável /t,d/ diante de [u], segundo o grupo de fatores pausa

\begin{tabular}{c|c|c|c|c}
\hline \multirow{2}{*}{$\begin{array}{c}\text { Contexto } \\
\text { Linguístico }\end{array}$} & \multicolumn{3}{|c}{ [t, d] } & \multicolumn{2}{c}{ Variantes } \\
\cline { 2 - 5 } & Ocorrência & Porcentagem & Ocorrência & Porcentagem \\
\cline { 2 - 5 } & Ocem & $52 / 123$ & $42 \%$ \\
\hline Pausa & $71 / 123$ & $58 \%$ & $13 / 244$ & $5 \%$ \\
\hline Sem pausa & $231 / 244$ & $94 \%$ & \multicolumn{4}{c}{$\%$} \\
\hline
\end{tabular}

O resultado mais saliente observado na Tabela 3 é o que aponta para um percentual bastante baixo de realização da variante oclusiva aspirada em contexto sem pausa, uma vez que temos, nesse contexto, apenas $5 \%$ de ocorrências dessa variante. Já o contexto de pausa é o que se mostra como campo propício à variação, pois o percentual de uso das duas variantes está mais equilibrado (58\% de oclusiva alveolar e $42 \%$ de oclusiva aspirada). Assim, podemos dizer que o contexto de pausa parece favorecer a produção da variante aspirada. Para exemplificar, extraímos o seguinte trecho da fala do Informante 1:

(2) [...] mas tem alguns que são fora de mão, né...tem uns que eles botam (6) ['põnt thu]....eu acho né...eu acho...que eles botam (7) ['sextu] (8) ['põntu] de ônibus em lugar onde não tem ninguém, e onde precisa eles não botam [...] (Inf. 01)

Nota-se que o Informante 1 produziu o mesmo vocábulo ponto com a variante oclusiva simples (6) e com a aspirada (8), porém, na primeira o contexto era de pausa, enquanto, na segunda, não havia pausa, mas um contexto que, possivelmente, interfere no condicionamento da variante ([de]). Nesse trecho, aparece também a palavra certo (7), produzida com a variante sem aspiração [t], em contexto sem pausa ${ }^{12}$.

Esse resultado, que era o esperado, está em harmonia com o estudo de Pagotto (2004). No trabalho de Pagotto, o contexto de pausa mostra-se relevante para a produção da africada e, no presente estudo, esse contexto mostra-se relevante para a aspirada. Lembrando que o autor inclui as aspiradas no grupo das africadas devido a sua semelhança articulatória. Assim, é provável que, linguisticamente, a pausa esteja exercendo influência na produção do fenômeno de aspiração.

Além disso, podemos relacionar o resultado do contexto pausa com o resultado apresentado na seção anterior, o contexto leitura, que também favoreceu o aparecimento da aspiração. É interessante lembrar que o dialeto florianopolitano se caracteriza pelo ritmo acelerado de fala, como aponta Furlan (1989). Isso pode justificar o fato de que tenha aparecido mais

\footnotetext{
${ }^{12}$ Os números entre parênteses se referem, na transcrição dos dados, às ocorrências da variável controlada, /t,d/ diante de [u], conforme ilustrado no anexo.
} 
aspiração nas leituras do texto e das frases dirigidas, pois nesses contextos os informantes tenderam a falar mais devagar, produzindo mais pausas.

Outro fato que chamou a atenção foi a diferença de ocorrências entre a variante aspirada surda e a sonora. A Tabela 4 ilustra o resultado:

TABELA 4. Resultado da variante aspirada $\left[\mathrm{t}^{\mathrm{h}}, \mathrm{d}^{\mathrm{h}}\right]$ em realização surda e sonora

\begin{tabular}{|c|c|c|c|}
\hline \multicolumn{4}{|c|}{ Variante aspirada $\left[\mathrm{t}^{\mathrm{h}}, \mathrm{d}^{\mathrm{h}}\right]$} \\
\hline \multicolumn{2}{|c|}{ Surda $\left[\mathrm{t}^{\mathrm{h}}\right]$} & \multicolumn{2}{|c|}{ Sonora $\left[d^{\mathrm{h}}\right]$} \\
\hline Ocorrência & Porcentagem & Ocorrência & Porcentagem \\
\hline $55 / 65$ & $85 \%$ & $10 / 65$ & $15 \%$ \\
\hline
\end{tabular}

A partir da Tabela 4, percebe-se que a aspiração ocorreu predominantemente sobre a variante surda, enquanto a surda $\left[\mathrm{t}^{\mathrm{h}}\right]$ teve 55 ocorrências, correspondendo a $85 \%$ de um conjunto de 65 palavras, a sonora apareceu em apenas 10 produções, representando $15 \%$. Esse resultado se mostra em conformidade com os dados observados por Alves et al. (2008) em relação à ocorrência de aspiração nas oclusivas surdas no português do Brasil. Ou seja, os falantes entrevistados para esta pesquisa produzem a variante oclusiva alveolar aspirada, sobretudo quando ensurdecidas.

\subsection{Os grupos de fatores sociais idade e sexo}

A idade foi analisada em dois fatores: entre 20 e 30 anos (três informantes) e entre 40 e 50 anos (três informantes), conforme mostra a Tabela 5.

TABELA 5. Resultado da variável /t,d/ diante de [u], segundo o grupo de fatores idade

\begin{tabular}{c|c|c|c|c}
\hline \multirow{2}{*}{$\begin{array}{c}\text { Fator Social } \\
\text { Idade }\end{array}$} & \multicolumn{3}{|c}{ Variantes } \\
\cline { 2 - 5 } & \multicolumn{2}{|c}{ [t, d] } & \multicolumn{2}{c}{ [t $^{\left.\mathbf{h}, \mathbf{d}^{\mathbf{h}}\right]}$} \\
\cline { 2 - 5 } & Ocorrência & Porcentagem & Ocorrência & Porcentagem \\
\hline Entre 20 e 30 anos & $161 / 186$ & $86 \%$ & $25 / 186$ & $13 \%$ \\
\hline Entre 40 e 50 anos & $141 / 181$ & $78 \%$ & $40 / 181$ & $22 \%$ \\
\hline
\end{tabular}

No grupo entre 40 e 50 anos, houve maior ocorrência de aspiração se comparado ao grupo entre 20 e 30 anos. A percentagem da produção de aspiradas relativa ao grupo dos mais velhos foi de $22 \%$, a dos mais jovens foi de apenas 13\%. Esse número contrasta com o resultado do estudo de Pagotto (2004), que mostra os mais jovens produzindo mais a variante africada.

A Tabela 5 mostra uma diferença de $11 \%$ entre os dois grupos. Embora a diferença se mostre pequena, é interessante notar que a variante aspirada está mais presente na fala do grupo entre 40 e 50 anos, contrapondo-se ao resultado esperado, ou seja, o de encontrar mais aspiradas na fala dos jovens. 
O grupo de fatores sexo foi analisado em dois condicionantes: masculino (três informantes) e feminino (três informantes), conforme mostra a Tabela 6.

TABELA 6. Resultado da variável /t,d/ diante de [u], segundo o grupo de fatores sexo

\begin{tabular}{c|c|c|c|c}
\hline \multirow{2}{*}{$\begin{array}{c}\text { Fator Social } \\
\text { Sexo }\end{array}$} & \multicolumn{2}{|c}{ [t,d] } & \multicolumn{2}{c}{ Variável /t,d/ } \\
\cline { 2 - 5 } & $\begin{array}{c}\text { Ocorrências/ } \\
\text { Total }\end{array}$ & Porcentagem & $\begin{array}{c}\text { Ocorrência/ } \\
\text { Total }\end{array}$ & Porcentagem \\
\hline Masculino & $142 / 188$ & $75 \%$ & $46 / 188$ & $24 \%$ \\
\hline Feminino & $160 / 179$ & $89 \%$ & $19 / 179$ & $10 \%$ \\
\hline
\end{tabular}

No que tange ao fenômeno enfatizado no trabalho, a aspiração, podemos perceber um pequeno aumento do número de ocorrências de $\left[\mathrm{t}^{\mathrm{h}}, \mathrm{d}^{\mathrm{h}}\right]$ no grupo masculino. A produção de aspiradas ocorreu em $24 \%$ do conjunto de dados do grupo do masculino, enquanto os dados referentes ao grupo feminino mostraram apenas 10\% de produção de aspiração.

Apesar da pequena diferença de porcentagem entre os gêneros, cabe mencionar que os homens realizaram um número maior de aspiração, contrariamente ao que era esperado, conforme a hipótese da relação entre o gênero feminino e o processo de africação, mencionada em Haeri (1996, apud PAGOTTO, 2004, p. 406).

\section{CONSIDERAÇÕES FINAIS}

O estudo evidenciou a ocorrência do fenômeno de aspiração no segmento oclusivo alveolar /t, d/ antes de vogal alta [u] na região de Florianópolis. Embora o sistema fonético do português não apresente a coronal anterior aspirada, pode-se perceber que os informantes fizeram uso do segmento aspirado $\left[\mathrm{t}^{\mathrm{h}}\right]$ e $\left[\mathrm{d}^{\mathrm{h}}\right]$ antes da vogal alta posterior.

Entre os fatores controlados, considerando-se os resultados percentuais, pode-se dizer que o linguístico mostrou-se mais relevante, seguindo-lhe os grupos de fatores sociais sexo e idade. Com relação ao primeiro, nota-se que o contexto pausa se destacou sobremaneira em termos percentuais. Quanto ao sexo e idade, as diferenças percentuais foram menos significativas, mas chamou a atenção o fato de os dados obtidos de ambos os grupos sociais observados não estarem em conformidade com os resultados previstos.

Cabe lembrar que o estudo constitui-se de uma análise baseada na fala de poucos informantes e que, pelo fato de que inúmeros fatores podem incidir sobre a fala dos participantes, como profissão, escolaridade etc., não cabe à conclusão do trabalho fazer generalizações ou determinar fatores definitivos.

Em um viés histórico, a variação de oclusivas apareceu registrada entre as características do falar açoriano em Florianópolis; em um momento, condicionada pelo contexto anterior, como vimos em Furlan (1989), e em outro pelo contexto seguinte, conforme Pagotto (2004). Isso indica uma sensibilidade da variável /t,d/ à cadeia sonora, o que está sendo 
observado nos estudos que consideram a gradiência dos processos fonológicos, mencionados por Cristófaro Silva (2006).

É importante ainda salientar a dificuldade em identificar auditivamente o fenômeno da aspiração. Como foi mencionado, há uma ampla margem entre uma oclusiva de fato e uma africada, em cujo meio se dão processos como a aspiração, africação e palatalização. Um caminho alternativo de análise é usar a metodologia da instrumentação acústica.

Retomando a questão sobre o discreto como parâmetro de categorização de segmentos na cadeia sonora, podemos questioná-lo diante de casos em que um segmento discreto ora se realiza com articulação secundária, ora não. Um detalhe como a aspiração, que se mostra mais frequente do que se pensava, mas que ora aparece, ora não, pode fazer parte do quadro fonético do português?

Acreditamos que a oclusiva aspirada pode ser vista como uma variante se consideramos o fenômeno de aspiração não somente como um detalhe acústico, senão como parte da variabilidade que envolve o segmento oclusivo. Ou seja, entre as várias possibilidades de realização da oclusiva alveolar, existe uma que se caracteriza por apresentar aspiração ao realizar-se na fala. Estudos mais exaustivos se fazem importantes na tentativa de explicitar melhor esse fenômeno.

\section{REFERÊNCIAS}

ALVES, Mariane Antero et al. On the Voiceless Aspirated Stops in Brazilian Portuguese. A. Teixeira et al. (Eds.): PROPOR, LNAI 5190, pp. 248-251, 2008.

BATTISTI, Elisa et al. Palatalização das Oclusivas alveolares e a rede social dos informantes. Revista virtual de Estudos da Linguagem - ReVEL. Vol. 5 n. 9, agosto de 2007.

BISOL, Leda. Introdução a estudos de fonologia do português brasileiro. Porto Alegre, RS: EDIPUCRS. 2a edição revista, 1999.

CAGLIARI, Luiz Carlos. Fonologia do português: análise pela geometria dos traços. Campinas, SP. Edição do Autor. $2^{\circ}$ edição revista, 1998.

CHO, Taehong; LADEFOGED, Peter. Variation and universals in VOT: evidence from 18 languages. Journal of Phonetics, Los Angeles, v. 27, p. 207-229, 1999.

FURLAN, Oswaldo A. Influência Açoriana no português do Brasil - em Santa Catarina. Florianópolis, SC. Editora da UFSC, 1989.

INSTITUTO BRASILEIRO DE GEOGRAFIA E ESTATÍSTICA (IBGE). Informações estatísticas de Florianópolis, SC. In www.ibge.gov.br/cidades. 
LABOV, W. Sociolinguistic Patterns. Philadelphia: University of Pennsylvania Press, 1972.

PAGOTTO, Emílio G. Variação e (') identidade. Maceió: EDUFAL, 2004.

PIRES, Lisiane B. A palatalização das oclusivas dentais em São Borja. Revista Virtual de Estudos da Linguagem - ReVEL. Edição especial n. 1, 2007.

CRISTÓFARO SILVA, Thaïs. Fonética e Fonologia: Perspectivas Complementares. In: Estudos da língua(m) - Questões de Fonética e Fonologia. Uma homenagem a Luiz Carlos Cagliari. Belo Horizonte: Vitória da Conquista, 2006. 


\section{ANEXO 1}

\section{Roteiro de entrevista}

Dados do informante:

1) Idade:

2) Sexo:

3) Naturalidade:

4) Origem:

5) Escolaridade:

Parte I - Livre

1) Fale um pouco da sua família (pai, mãe, irmãos, esposo(a), namorado (a), filhos).

2) Qual é a sua profissão? Fale um pouco sobre ela.

3) Você utiliza ônibus? Você gosta do tipo de ponto de ônibus?

4) Você acha que o turismo é importante em Floripa?

5) Você acha que o trânsito na cidade é um problema?

Parte II - Leitura do texto: Leia o texto individualmente e, em seguida, leia-o em voz alta:

Existe vacina contra a nova gripe?

Sim, (1) muitos laboratórios estão (2) testando a nova vacina para humanos. Elas só serão liberadas para uso em grande escala após terem (3) mostrado, (4) durante os testes, eficácia e segurança. A previsão é que isso aconteça a partir de setembro, antes do início (5) oㅡ inverno no hemisfério norte. Será um (6) produto diferente da vacina chamada sazonal que já foi feita para este ano. (7) Portanto, serão (8) utilizados os dois (9) métodos para proteção da gripe. Os (10) estudos até o (11) momento, sobre a vacina contra a nova gripe, dizem (12) respeito à capacidade de produção (13) dos laboratórios, como distribuir a vacina entre os países e se há prioridade de vacinação para (14) certos grupos de (15) indivíduos: idosos, crianças e (16) adultos.

Adaptado de Diário Catarinense. www.clicrbs.com.br/diariocatarinense. Visitado em 05/08/2009.

Contextos lingüísticos controlados no texto: Pausa: 3, 7, 15, 16. Sem pausa: 1, 2, 4-6, 8-14.

Parte III - Leitura das frases dirigidas: Leia as frases abaixo.

$\begin{array}{lll}\text { 1. O universo é vasto } & \text { 8. Avião a jato } & \text { 15. Pontos de ônibus } \\ \text { 2. Bonito fado } & \text { 9. Com respeito } & \text { 16. Os gatos negros } \\ \text { 3. Um momento } & \text { 10. Sem jeito } & \text { 17. Muro de concreto } \\ \text { 4. Meu mundo } & \text { 11. Tudo bem } & \text { 18. No bom sentido } \\ \text { 5. Vinho do Porto } & \text { 12. Dunas brancas } & \text { 19. Eduardo Almeida } \\ \text { 6. Olho torto } & \text { 13. Muito astuto } & \text { 20. Um duelo famoso } \\ \text { 7. Bicho chato } & \text { 14. Grande cardume } & \text { 21. Época de turismo }\end{array}$

22. Durante o período

23. Grande túmulo

24. Dúvida cruel

25. Não vi o Tuco

26. Ele não educa bem

21. Época de turismo

Contextos lingüísticos controlados nas frases dirigidas: Pausa: 1-10, 13, 17,18. Sem pausa: 11, 12, 14$16,19-26$ 


\section{ANEXO 2 \\ Parte da transcrição fonética dos vocábulos analisados}

\section{Informante 1: 48 anos - sexo masculino}

\section{Parte I: Fala espontânea}

\section{Questão 3}

Olha, na minha época, a gente ia pra escola de carroça....pra (1) [tu] ter uma idéia, o leite era entregue dentro de garrafa de vidro....Dentro daquilo que existia pra hoje, assim melhorou em termos, tem mais em quantidade, mas em contrapartida, ta um monopólio...sabes que ta um monopólio... são dois ou três

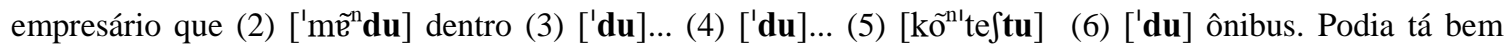
melhor, podíamos ter o transporte marítimo...poderiam fazer ciclovias, pra (7) [tu] ver, a única ciclovia que a

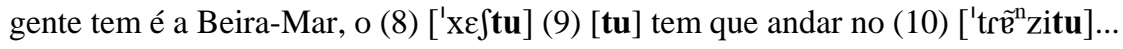

\section{Questão 4}

Ó..ió..ió se não é...inclusive, acho que eles deviam investir um pouco mais na...na...porque é...é o que traz pra nós realmente...sabes que (11) [' $\mathrm{k}^{\mathrm{w}} \tilde{\mathfrak{e}}^{\mathrm{n}} \mathbf{d u}$ ] chega a temporada de verão...(12) ['todu] (13) ['mũ $\left.\tilde{\mathrm{d}}^{\mathrm{n}} \mathbf{d u}\right]$ sobrevive... (14) [' $\left.\mathbf{k}^{\mathrm{w}} \tilde{\boldsymbol{e}}^{\mathrm{n}} \mathbf{d u}\right]$ chega a época que ...eles dizem..vaca magra....mês de abril, maio, junho julho, agora (15) [a'goft $\left.\mathbf{t}^{\mathbf{h}} \mathbf{u}\right] \ldots$, daí em setembro a coisa começa a funcionar

\section{Questão 5}

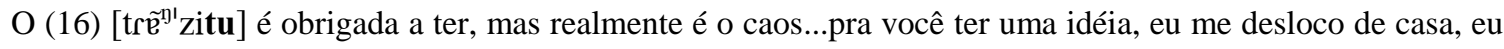
vou...ou eu vou de ônibus...e como eu (17) ['goftu] de correr, fazer maratona, eu me predisponho a ir (18) [ko'xễ $\left.\tilde{n}^{\mathrm{n}} \mathbf{d u}\right] . .$. , eu faço quarenta (19) [mi'nutu] pra ir lá no hospital infantil, de carro (20) [tu] leva quarenta (21) [mi'nutu] pra ir até o centro....

Contextos lingüísticos observados na parte I: Pausa: 3, 4, 10, 15, 18 Sem pausa: 1, 2, 5-9, 11-14, 16, 17, 1921

\section{Parte II: Leitura do texto (transcrição dos vocábulos controlados)}

1 muitos: ['muĩ tus]

2 testando: [tes' ${ }^{\prime} \tilde{e}^{\mathrm{n}} \mathbf{d u}$ ]

3 mostrado: [mos'trad ${ }^{\mathrm{h}} \mathbf{u}$ ]

4 durante: [du'r $r \tilde{e}^{n} \mathrm{t} \int \mathrm{I}$ ]

5 do: ['du]

6 produto: [pro'dutu]
7 portanto: [pox't $\mathfrak{t e}^{\mathrm{n}} \mathbf{t}^{\mathrm{h}} \mathbf{u}$ ]

8 utilizados: [utzili'zaduf]

9 métodos: ['metuduf]

10 estudos: [is'tuduf]

11 momento: [mo'men $\tilde{e}^{\mathrm{n}} \mathbf{t}^{\mathrm{h}} \mathbf{u}$ ]

12 respeito: [xef'pejtu]
13 dos: ['dus]

14 certos: ['sextuf]

15 indivíduos: [ [1 di'vidu: $\left.\int\right]$

16 adultos: [a'du: $\mathbf{t}^{\mathbf{h}} \mathbf{u} \int$ ]

Contextos lingüísticos observados na parte II: Pausa: 3, 7, 11, 15, 16. Sem pausa: 1, 2, 4-6, 8-10, 12-14

\section{Parte III: Leitura de frases dirigidas (transcrição dos vocábulos controlados)}
1 vasto: ['vast $\left.\mathbf{t}^{\mathrm{h}} \mathbf{u}\right]$
3 momento: [mo'mẽt $\left.{ }^{\text {h }} \mathbf{u}\right]$
5 porto: ['poxt $\left.{ }^{\mathrm{h}} \mathbf{u}\right]$
2 fado: ['fadu]
4 mundo: $\left[\mathrm{mu}^{\mathrm{n}} \mathbf{d}^{\mathbf{h}} \mathbf{u}\right]$
6 torto: ['toxt $\mathbf{t}^{\mathrm{h}} \mathbf{u}$ ] 
7 chato: [' $\left.\int \mathbf{a t}^{\mathrm{h}} \mathbf{u}\right]$

8 jato: ['zatu]

9 respeito: [xeك'pejtu]

10 jeito: ['zejtu]

11 tudo: ['tudu]

12 dunas: ['dunes]

13 astuto: [as'tut ${ }^{\mathrm{h}} \mathrm{u}$ ]
14 cardume: [kax'dume]

15 pontos: [po $\left.{ }^{\mathrm{n}}{ }^{\mathrm{t}} \mathrm{tu}\right]$ ]

16 gatos: ['gatuf]

17 concreto: [kôn $\left.{ }^{\text {nI }} \mathrm{kret}^{\mathrm{h}} \mathrm{u}\right]$

18 sentido: [se $\left.\mathrm{e}^{\mathrm{n}} \mathrm{t} \mathrm{fidu}\right]$

19 Eduardo: [edu'axdu]

20 duelo: [du'clu]
21 turismo: [tu'rizmu]

22 durante: [du'c $\left.\tilde{e}^{n} t f i\right]$

23 túmulo: ['tumulu]

24 dúvida: ['duvide]

25 Tuco: ['tuku]

26 educa: [e'duke]

Contextos lingüísticos observados na parte III: Pausa: 1-10, 13, 17,18. Sem pausa: 11, 12, 14-16,19-26 